\title{
Solvent-Free Microwave Extraction of Essential Oil and Hydrosol From Piper Longum Lour. Fruit and Evaluation of Antioxidant Activities
}

\author{
Fei Song \\ Coconut Research Institute \\ Liyun Huang \\ Coconut Research Institute \\ Weiquan Qin \\ Coconut Research Institute \\ Hua Chen ( $\nabla$ ch111666@126.com ) \\ Coconut Research Institute \\ Liyun liu \\ Coconut Research Institute \\ Minmin Tang \\ Coconut Research Institute
}

\section{Research Article}

Keywords: Solvent-free microwave assisted extraction, Piper longum L., Essential oil, Hydrosol, Antioxidant activities

Posted Date: January 25th, 2021

DOI: https://doi.org/10.21203/rs.3.rs-148916/v1

License: (9) This work is licensed under a Creative Commons Attribution 4.0 International License. Read Full License 


\section{Abstract}

In this study, essential oil (EO) of Piper longum L. $(P L)$ fruit was extracted by solvent-free microwave assisted extraction (SFME) and hydroditillation (HD) with hydrosol obtained as a by-product. Operational conditions for SFME were maximized by response surface methodology (RSM) combined with a Box-Behnken design (BBD). Results indicated that the maximum extraction rate of EO by SFME with the optimal parameters was $0.747 \%$, which was significantly higher than $0.496 \%$ of HD method. The EOs analyzed by GC-MS, presented 50 and 36 compounds constituting $95.99 \%$ and $98.52 \%$ of the total peak area obtained by SFME and HD, respectively. The principal components of the both oils were sesquiterpenes and aliphatics while SFME EO contained more bioactive compounds of terpenoids. The predominant components of SFME and HD hydrosols were eugenol (25.44\% SFME; $22.82 \% \mathrm{HD}$ ) and linalool (14.10\% SFME; $22.37 \% \mathrm{HD}$ ). Trans-isoeugenol, observed for the first time in $P L$ fruit, was presented in SFME hydrosol and took up $14.33 \%$ of all the detected compounds. Both the EO and hydrosol extracted by SFME possessed better antioxidant properties than those from HD method, which indicated that SFME was a superior approach to simultaneously obtain the two products.

\section{Introduction}

Piperlongum L. (PL, Piperaceae), commonly known as "long pepper", is widely distributed in the tropical and subtropical regions of the world, throughout the South Asian Subcontinent, Sri Lanka, Middle Eastern countries, the Americas and China 1'2. It is said that long pepper was valued more highly than black pepper due to its high commercial and economical importance in ancient Rome. In Ayurvedic medicine, the fruit is said to be a good rejuvenator. Now, $P L$ fruit is used as a component of popular medicines to cure diseases like leprosy, tuberculosis, gonorrhoea, menstrual pain, sleeping problems, respiratory tract infections, chronic gut related pain and arthritic conditions 1,3.4. Based on recent research, $P L$ fruit contains a series of alkaloids 5 , resin, organic acids, volatile oil, and terpenoid substances 6 . The fruit displays a wide spectrum of pharmacological activities, including anthelmintic activity 7 , antioxidant, anti-inflammatory, and antitumor activities $1,8,9$, and has protective effects on injured neuron 10 , hair cell and hepar $10,11$.

Essential oils (EOs) are complex mixtures of volatile compounds, including diverse terpenes and their oxygenated derivatives such as alcohols, phenols, ketones, which were uniformly called terpenoids. They are considered to be one of the most important chemical groups in plants and to possess antibacterial and antioxidant 12-14, antifungal 15,(Gulluni, Re et al. 2018) antiinflammatory activities 16,17 , and extending shelf life of packaged food 18. Another representative chemical family of EO was phenylpropanoids such as eugenol, conyferial alcoho, guaiacol, and et a/ 19. Various different methods can be used for essential oil extraction, including traditional methods such as hydro-distillation, steam distillation, Soxhlet extraction, and as well as emerging innovative and promising methods such as supercritical fluid extraction, microwave assisted extraction (MAE) and ultrasonic assisted extraction (UAE). In recent years, Solvent-free microwave extraction (SFME) of essential oils has attracted researchers' tremendous interest because of its higher efficiency, less solvent, lower energy exhaustion, and less labor output 20. Hydrosol, also called hydrolate or floral water, is the hydrophilic fraction can be obtained during EO extraction process as a byproduct. Owing to their biological and aromatic properties hydrosols have been commercially used more popuparly in aromatic waters are used in the food and daily chemical products industries, along with aromatherapy and agriculture 21. Global demand of hydrosols is ever growing and the market value is projected to reach USD 437 million by the end of 2024.

$P L$ fruit contains $1 \%$ volatile oil, mainly composed by caryophyllene, pentadecane and bisaboline. To our best knowledge, there have been several reports about the chemical compositions of the essential oil extracted by conventional methods from $P L$ fruit, but no data is available in the literature concerning the antioxidant activity of the essential oil and hydrosol of the fruit. The objectives of this study were to analyze the volatile chemical composition of essential oils and hydrosols from $P L$ fruit by SFME compared with HD, and to provide scientific evidence to justify the antioxidant activities of the two products.

\section{Methods}

\subsection{Chemicals and raw materials}


Ascorbic acid, 2,2-azino-bis(3-ethylbenzothiazoline-6-sulfonic acid) (ABTS), butylatedhydroxyl- toluene (BHT), 1,1-diphenyl-2picrylhydrazyl (DPPH), ferric chloride, potassium ferricyanide, sodium phosphate, and 2,4,6-tris(2-pyridyl)-1,3,5-riazine (TPTZ) were purchased from Sigma-Aldrich Chemie (Steinheim, Germany). All other solvents and chemicals were of analytical grade and obtained from Merck \& Co. (Kenilworth, NewJersey, USA) and BDH Chemicals Ltd. (Poole, Dorset, UK). The PL fruit were purchased commercially and grounded into powder.

\subsection{Extraction of essential oils and hydrosols}

\subsubsection{Solvent-free microwave extraction}

SFME was performed in a laboratory microwave-accelerated reaction system as shown in Fig. 1 (MCR-3, KERUI, China). This is a $(2450 \pm 50) \mathrm{MHz}$ multimode microwave reactor with a maximum output power of $750 \mathrm{~W}$ delivered in $1 \mathrm{~W}$ increments. This instrument is equipped with an infrared temperature sensor, an electromagnetic stirrer, and a circulating water-cooling system. The microwave irradiation time, and irradiation power can be controlled by an electronic control panel. For SFME procedure, an aliquot of $100 \mathrm{~g} \mathrm{PL}$ fruit powder was wetted before extraction by splashing certain percentage of water evenly and the wetted material was put into a flask to place into the reactor. Essential oil and hydrosol were simply separated with a built-in separatory funnel of the instrument. The isolated oil was dried by anhydrous sodium sulphate and weighed. The extraction yield of essential oil was calculated according to the equation given:

$$
\text { Extraction yield }(\%, w / w)=\frac{\text { Mass of extracted essential oil }}{\text { Mass of dried material }} \times 100
$$

\subsubsection{Single factor study of SFME}

The single-factor study was carried out to evaluate the preliminary range of extraction variables including microwave irradiation power $\left(\mathrm{X}_{1}\right)$, microwave irradiation time $\left(\mathrm{X}_{2}\right)$, and percentage humidity of the matrix $\left(\mathrm{X}_{3}\right)$ in SFME.

Hundred grams dried sample was moistened prior extraction by splashing $60 \mathrm{~mL}$ water evenly to the material prior extraction to 60 percentage humidity of the matrix prior extraction. And then moistened fruit powder was placed in the reactor of different microwave power (150 750W) for $40 \mathrm{~min}$.

Hundred grams dried sample was moistened by splashing $60 \mathrm{~mL}$ water evenly to the material prior extraction to 60 percentage humidity of the matrix prior extraction. And then moistened fruit powder was placed in the reactor of $600 \mathrm{~W}$ microwave irradiation power with different microwave irradiation time (20 60 min).

Hundred grams dried sample was moistened by splashing water evenly to the material prior extraction to get different percentages humidity of the matrix (40 90\%). And then moistened fruit powder was placed in the reactor of $600 \mathrm{~W}$ microwave powers for 30 $\min$.

\subsubsection{Optimization of factors by BBD}

On the basis of the single-factor test results, three factors at three levels Box-Behnken design (Design Expert software, Trial Version 8.0.6, Stat-Ease Inc., Minneapolis, MN) was employed to optimize the extraction conditions and to explore the effects of individual and the interaction between the factors on the essential oil yield. Table 1 listed the Box-Behnken design matrix, coded and real forms of each independent variable at three levels $(+1,0$ and -1$)$, the experimental value from the SFME performed, and the anticipated response obtained through calculation.

In order to determine the maximum point of response, experimental data was fitted to a quadratic polynomial model and regression coefficients obtained. The non-linear quadratic model used in the response surface presented below:

$$
\mathrm{Y}=\beta_{0}+\sum_{i=1}^{n} \beta_{i} X_{i}+\sum_{i=1}^{n} \beta_{i i} X_{i}^{2}+\sum_{\substack{i=1 \\ i<j}}^{n-1} \sum_{j=2}^{n} \beta_{i j} X_{i} X_{j}+\varepsilon
$$


Where $\mathrm{Y}$ is the response variable, $X_{i}$ and $X_{j}$ were the independent values of variables, and $\beta_{0,} \beta_{i,} \beta_{i j} \beta_{i j}, n$ and $\varepsilon$ were the model coefficients of the intercept, linear, quadratic, and interaction coefficients, the number of the independent variables and the experimental error, respectively.

\subsubsection{Hydrodistillation (HD)}

Conventional hydrodistillation apparatus (Clevenger-type apparatus) according to the European Pharmacopeia was used in this procedure. An aliquot of $300 \mathrm{~g}$ materials was hydrodistilled with $1.5 \mathrm{~L}$ of water in a glass reaction flask for $6 \mathrm{~h}$ (until no more essential oil obtained). The essential oil was collected, dried under anhydrous sodium sulphate, and stored at $4{ }^{\circ} \mathrm{C}$ until further analysis. Each extraction was done at least three times, and a standard deviation was calculated.

\subsection{Chemical analysis}

GC-MS analysis of the essential oil were carried out on an Aglient HP 7890A-5975C GC-MS, equipped with a 7693A auto injector (Agilent Technologies Inc., PA, USA) and a capillary column (Agilent HP-5 MS, cross-linked 5\% phenyl polysilphenylene-siloxane, 30 $\mathrm{m} \times 0.25 \mathrm{~mm} \times 0.25 \mu \mathrm{m}$ film thickness). The column oven temperature was programmed from an initial temperature of $100{ }^{\circ} \mathrm{C}(2$ min) to $250{ }^{\circ} \mathrm{C}(20 \mathrm{~min})$ at $4{ }^{\circ} \mathrm{C} / \mathrm{min}$. The column temperature was programmed at $50^{\circ} \mathrm{C}$ for $5 \mathrm{~min}$ and at $250{ }^{\circ} \mathrm{C}$ for $10 \mathrm{~min}$. The injection temperature and ion source temperature were 250 and $230^{\circ} \mathrm{C}$, respectively. A $2 \mu \mathrm{L}$ sample was injected in the split mode with a split ratio of $25: 1$. The ionizing energy was $70 \mathrm{eV}$. Alkanes $\left(\mathrm{C}_{8}-\mathrm{C}_{40}\right)$ were used as references in the calculation of retention indices (RI). The constituents of essential oils and hydrosols were identified by comparison of their retention indices and mass spectra with the NIST Mass Spectral Library (Agilent Technologies Inc., PA, USA).

\subsection{Total phenolic content of essential oils and hydrosols}

The total phenolic contents of EOs and hydrosols were determined according to the Folic-Ciocalteu colorimetric method, as proposed by 22 with a slight modification. Sample solution $(0.5 \mathrm{~mL})$ was added to $2.5 \mathrm{~mL}$ of 10 -fold diluted Folin-Ciocalteu's reagent. After an interval of $5 \mathrm{~min}, 2.0 \mathrm{~mL}$ of $7.5 \%(\mathrm{w} / \mathrm{w})$ sodium carbonate were added. The mixture reacted at room temperature for $30 \mathrm{~min}$, and the absorbance was recorded at $765 \mathrm{~nm}$ (Libra S35 UV/Vis-spectrophotometer, Biochrom Ltd., Cambridge, UK). Distilled water was invoked as a blank and gallic acid was used as the standard. The same procedure was repeated for all standard gallic acid solutions $(0 \sim 50 \mu \mathrm{g} / \mathrm{mL})$ to get a standard curve and the results were expressed as milligrams of gallic acid equivalents (GAE) per gram of essential oil ( $\mathrm{mg} \mathrm{GAE} / \mathrm{g}$ ) or microgram per milliliter of hydrosol $(\mu \mathrm{g} / \mathrm{mL})$. The analyses were repeated in triplicate and standard deviation was calculated. A standard curve was depicted by the following equation: Gallic acid concentration $(\mu \mathrm{g} / \mathrm{mL})=82.37 \times A_{765 \mathrm{~nm}}-2.0242, \mathrm{R}^{2}=0.9977$.

\subsection{Analysis of antioxidant activities}

\subsubsection{DPPH and $\mathrm{ABTS}^{+}$radicals scavenging $\mathrm{A}$}

Free radical scavenging activities of 2,2-diphenyl-1-picrylhydrazyl (DPPH) and azino-bis (ethylbenzothiazoline-6-sulfonic acid, $\mathrm{ABTS}^{\circ+}$ ) was determined by classical spectrophotometric methods with some corrections ${ }^{23,24}$. For the DPPH assay, different concentrations of the EOs in methanol $(0.1 \sim 10 \mathrm{mg} / \mathrm{mL})$ and hydrosols in distilled water (2 100\%) were added to $2 \mathrm{~mL}$ of a 0.15 $\mathrm{mM}$ solution of DPPH. The mixture was shaken vigorously to be homogenous. After incubated in a dark place for $30 \mathrm{~min}$ at room temperature, the absorbance decrease at $517 \mathrm{~nm}$ of the reacting solution was recorded. In the ABTS ${ }^{\circ+}$ test, the prepared radical solution was attenuated with methanol to an absorbance of $0.700 \pm 0.02$ at $734 \mathrm{~nm}$. After $100 \mu \mathrm{L}$ of sample solution reacted with $1.0 \mathrm{~mL}$ of $\mathrm{ABTS}^{-+}$solution for $30 \mathrm{~min}$ at room temperature, the absorbance at $734 \mathrm{~nm}$ would be recorded. The radical solutions added with the equal amount of the corresponding sample diluents were used as control and tests were carried out in triplicate. The percentage inhibition was calculated as $(1 \%)=\left(A_{0}-A\right) / A_{0} \times 100$, where $\mathrm{A}_{0}$ is the absorbance of control without adding antioxidants, and $A$ represents the absorbance of the samples. The $\mathrm{IC}_{50}$ value was calculated as the concentration of the sample needed to scavenge $50 \%$ of free radicals by graphing the linear curve of $1 \%$ versus sample concentration. BHT (butylated hydroxytoluene) was used as a positive control compared with the essential oils and ascorbic acid as a positive control for the hydrosols. 


\subsubsection{Reducing power assay}

The reducing power of EOs and hydrosols was performed following the standard method 25 with a little modification. $0.2 \mathrm{~mL}$ sample at different concentrations was added $1.0 \mathrm{~mL}$ of $0.2 \mathrm{M}$ phosphate buffer $(\mathrm{pH} 6.6)$ and $1.0 \mathrm{~mL}$ of $1 \%$ potassium ferricyanide. The mixtures were incubated in a water bath at $50{ }^{\circ} \mathrm{C}$ for $20 \mathrm{~min}$. Then, $1.0 \mathrm{~mL}$ of $10 \%$ trichloracetic acid was added into the mixture to terminate the reaction. The resulted solution was mixed with an equal amount of distilled water and $0.1 \mathrm{~mL}$ of $0.1 \%$ ferric chloride $\left(\mathrm{FeCl}_{3}\right)$ solution for $10 \mathrm{~min}$. Then, the absorbance of mixture was measured at $700 \mathrm{~nm}$ against blank solution

\subsection{Statistical analysis}

Statistical analysis was performed using the SPSS 16.0 software program (Statistical Package for Social Sciences, Chicago, IL, USA). All experimental data were presented as the mean \pm SEM of the mean from at least three independent experiments. Statistical significance was assessed by one-way analysis of variance and Turkey test to examine differences between the two groups using SPSS version 16.0 (SPNN Inc., Chicago, IL, USA). $p$ values of less than 0.05 were considered statistically significant.

\section{Results And Discussion}

\subsection{Single factor study of SFME}

Solvent-free microwave extraction (SFME), an innovative technology combining microwaves and distillation, has been rapidly developed as one of the popular techniques to extract EO from plant materials. In this SFME process, microwave irradiation provides energy to heat in situ water generating pressured atmosphere. This tremendous pressure tends and ruptures the cell walls, which facilitates the aromatic compounds spreading over and subsequent dissolution. The increase of the microwave power improves the yield and leads to a shorter extraction time.

\subsubsection{Effect of microwave irradiation power on EO yield}

Microwave irradiation power can lead aromatic compounds to rapidly rotate and to leach out from the plant cells, while too high power will degrade volatile components and destroy the material. Thus, an appropriate microwave irradiation power setting is important in EO extraction. It can be observed from Fig. 1 that the EO yield increases with the increasing of microwave irradiation power (from 150 to $750 \mathrm{~W}$ ), and reaches a well-defined limit when the irradiation power of more than $750 \mathrm{~W}$ resulted in a slight decrease in the yield. Similar results were also obtained in previous studies $26 \cdot 27$. Whereas, there was no significant difference $(p<$ $0.05)$ of EO extraction yield at $600 \mathrm{~W}$ compared with the yield at $750 \mathrm{~W}$, which were $(0.733 \pm 0.035) \%$ and $(0.731 \pm 0.045) \%$, respectively. To lower energy consumption, microwave irradiation power in the range of $300 \sim 600 \mathrm{~W}$ was chosen for the subsequent optimization.

\subsubsection{Effect of microwave irradiation time on EO yield}

To choose proper microwave irradiation time is important for the SFME process because long irradiation time can issue in excessive energy accumulation, which will lead to degradation of plant material or loss of some volatile constituents 26 . As presented in Fig. 1, the EO yield gradually increased with the rise in microwave irradiation time from $10 \mathrm{~min}$ to $40 \mathrm{~min}$. After $40 \mathrm{~min}$, the yield reached a plateau denoting the maximum EO extracted. However, the EO yield at 50 min was $(0.728 \pm 0.020) \%$, which was not significantly different $(p<0.05)$ with the yield of $(0.733 \pm 0.035) \%$ at $40 \mathrm{~min}$. To promote efficiency of operations, $20 \sim 40 \mathrm{~min}$ was selected for the subsequent optimization by BBD.

\subsubsection{Effect of percentage humidity of the matrix on EO yield}

To obtain the suitable range of percentage humidity of the matrix for further optimization of the SFME procedure, the effect of this single factor on the $P L$ fruit EO extraction was evaluated at a fixed microwave irradiation time (30 min) and power (600 W) as shown in Fig. 2. An increase in percentage humidity of the matrix from $40-60 \%$ dramatically promoted extraction efficiency, which was likely due to the higher percentage humidity of the matrix generated higher evaporation pressure leading to more efficient extraction. However, further increase of percentage humidity of the matrix decreased the EO extracting efficiency after $60 \%$. This might because much higher humidity needed more heat to evaporate, and could result in the hydrolysis of some components and 
dissolution in water. Therefore, $50 \%$ 70\% was chosen as the suitable range of percentage humidity of the matrix for following optimization.

\subsection{Optimization of the procedure}

\subsubsection{Extraction model fitting and statistical analysis}

Based on the results of single factor experiments and design principle of BBD, response surface test of three factors and three horizontals was perforemed with microwave irradiation power $\left(X_{1}\right)$, microwave irradiation time $\left(X_{2}\right)$, percentage humidity of the matrix $\left(X_{3}\right)$ as independent variables and the essential oil yield $(Y)$ as the response value. The test results are shown in Table 1. In the experimental range, maximum value of $Y$ was $0.733 \%$ recorded under the experimental conditions of $X_{1}(600 \mathrm{~W}), X_{2}(40 \mathrm{~min})$, and $X_{3}(60 \%)$. By analyzing the exprimental data, the mathematical model equations of $Y$ and three independent variables are obtained as follows:

$Y=0.66+0.21 \times X_{1}-0.05 \times X_{2}+0.029 \times X_{3}+0.13 \times X_{1} \times X_{2}-0.052 \times X_{1} \times X_{3}+0.001 \times X_{2} \times X_{3}-0.13 \times X 21-0.076 \times X 22-0.066 \times X 23$

Results of the analysis of variance (ANOVA) for the fitted model were shown in Table 2. The regression model is extremely significant $(p<0.0001)$. Smaller value of lack of fit with greater $p$ value meant better fitness of the equation. For this caculated equation, mean square and $p$-value of the lack of fit was 0.0006 and 0.22 , respectively, which indicated that the unknown factors had little effect on the experimental results, and the predicted regression model fitted well with the test data. The value of $R^{2}$ for the model was 0.9982 , which indicated that only $0.18 \%$ of the total variations were not explained. The value of the adjusted determination coefficient (R2 adj $=0.9985)$, also confirmed that the model was significantly fitted and the experimental value of $P L$ EO yield was highly consistent with the predicted value. Therefore, the regression equation could essentially predict and analyze the yield of $P L$ fruit EO under most combination of the extraction variable values in the experimental range. The model terms having significant effects on essential oil yield $(p<0.05)$ were linear factors of $X_{1}, X_{2}$, and $X_{3}$, and quadratic ones of $X 21, X 22$, and $X 23$, while only one interaction term of $X_{1} X_{3}$ was also significant $(p<0.05)$. Based on the established model, the maximum predicted essential oil yield was $0.747 \%$. The optimal parameters were: microwave irradiation power $572.12 \mathrm{~W}$, microwave irradiation time $37.37 \mathrm{~min}$, and percentage humidity of the matrix $59.00 \%$, respectively.

\subsubsection{Analysis of response surface}

The graphical representations of the polynomial regression equation called three-dimensional response surfaces and contour plots were generated by Design Expert package as shown in Fig. 3.a-c. They illustrated the relationship between the essential oil yield and three extraction variables and the interactions between each two experimental variables. Elliptical and saddle-backed contour plot shows that the corresponding variables significantly interrelated ecah other, while circular contour plot explains that the interaction effects between the two investigated variables are negligible 28. In all the presented figures, the other one variable was kept at level zero.

At fixed percentage humidity of the matrix (60\%), both microwave irradiation power $\left(X_{1}\right)$ and time $\left(X_{2}\right)$ significantly influenced the $P L$ fruit EO yield in a quadratic manner, scilicet, increasing of the two variables to $594.81 \mathrm{~W}$ and 36.05 min could work out the highest essential oil yield $(0.745 \%)$ as shown in Fig. 3a. However, the contour shape of plot describing of the interaction effect of $X_{1}$ and $X_{2}$ on the yield was nearly circle, which indicated that the reciprocal action of microwave irradiation power and time on yield of $P L$ fruit EO was not significant (Fig. 3a), corresponding to the ANOVA results. Likewise, at a constant irradiation time (30 min), the augment in microwave power (up to $533.08 \mathrm{~W}$ ) and percentage humidity of the matrix (up to $65.80 \%$ ) brought out a corresponding increase of the EO yield, though further increase of the two variables lead to an obvious decrease of the response value as presented in Fig. 3b. Nevertheless, the contour line displaying the mutual interaction between microwave irradiation power and percentage humidity of the matrix is a sharp ellipse, which could prove that the interaction effect of the two independent factors on the dependent variable was significant. Although the mutual interaction between microwave irradiation time and percentage humidity of the matrix is an ellipse (Fig. 3c), it still can't be deduced that the interaction effect of $X_{2}$ and $X_{3}$ on $Y$ value was significant as the $p$ value was 0.8693 from the ANOVA for the model-fitting process.

\subsubsection{Optimization and validation of the models}


Based on the optimal conditions predicted by the Design-Expert software, confirmatory experiment of the adequacy of the model was performend with following modified parameters for operational feasibility: microwave irradiation power $\left(\mathrm{X}_{1}\right)$ of $572 \mathrm{~W}$, microwave extraction time $\left(X_{2}\right)$ of 37.50 min, and percentage humidity of the matrix $\left(X_{3}\right)$ of $59.00 \%$. The experimental yield of EO was $0.747 \pm 0.005 \%(n=3)$, being not significantly different with the predicted maximum value, but much higher than the yield of the HD method, which was $(0.496 \pm 0.021) \%$. Thus, those adoptive conditions were recommended for future SFME of EO from $P L$ fruit.

\subsection{Chemical compositions of EOs}

According the reported defenition, terpenes, phenylpropanes and their oxygenated substances, comprising of phenolic compounds, sometimes accounted among the majority of molecules in several EOs' composition 19. From the most studies in being, EO of $P L$ fruit possessed abundant amounts of sesquiterpenes, though there were variances in the contents of each ingredients according to differnet extraciton methods and extracting time 29-31. The chemical profiles of the EOs from $P L$ fruit extracted by SFME and HD were listed in Table 3. 50 and 36 components were identified, accounted for $95.99 \%$ and $98.52 \%$ of the two products, respectively. Sesquiterpenes were the first aboundant hydrocarbons of the EOs obtained by SFME and HD, having a high proportion up to $59.48 \%$ and $54.49 \%$, respectivly. These sesquiterpenes included germacerene $D(9.67 \%, 11.70 \%), \beta$-caryophyllene $(10.65 \%, 8.57 \%)$, $\beta$-selinene (5.05\%, 5.28\%), $\beta$-bisabolene (6.57\%, 6.85\%), humulene $(6.91 \%, 5.64 \%)$, zingiberene $(5.66 \%, 6.60 \%),(-)$-a-Panasinsen $(2.59 \%, 2.23 \%)$, and $\delta$-Cadinene $(1.49 \%, 1.07 \%)$. In addition, there were bits of sesquiterpenes named a-cubebene $(0.07 \%), \beta-$ elemene (2.30\%), epizonarene (0.72\%), bicycle[4.4.0]dec-1-ene, 2-isopropyl-5-methyl-9-methylene (0.27\%), $\gamma$-muurolene $(0.24 \%), \beta$ Cadinene $(0.23 \%)$, a-gurjunene $(0.22 \%),(+)$-epi-bicyclosesquiphellandrene $(0.12 \%)$, representing in SFME EO but not in HD EO. There were $5.19 \%$ and $2.46 \%$ of oxygenated compounds, substantially being oxygenated sesquiterpenes, in the oils extracted by SFME and HD, respectively. Another noticeable group of hydrocarbons in both SFME and HD EOs was aliphatics, such as pentadecane $(7.31 \%, 9.39 \%)$, 8-heptadecene $(6.75 \%, 10.29 \%)$, and heptadecane $(4.83 \%, 7.77 \%)$ in the each sample. Those results were in accord with some reports. EO of Melissa officinalis L. obtained by SFME contained $70.87 \%$ of oxygenous compounds and $29.08 \%$ of terpenes, which were higher than $63.09 \%$ and $27.32 \%$ of those two chemical groups in HD EO, respectively 32 . Thus, different heating types and water consumption in the tow different performatinons indeedly could affect the chemical compositions of the extracted EOs. Howerver, different influencing effects of SFME and HD occurred in different plant spieces. The content of oxygenous compounds was higher (75.06\%) in SFME EO than that of $62.46 \% \mathrm{n}$ HD sample while the contents of terpenes in the two EOs were in an opposite way 32. This phenomene was the same with the exploration about EOs extrcated by SFME and HD methods from pigeon pea leaves 33 and Zanthoxylum bungeanum Maxim 34. Therefore, it appeared that the influence of extracting methods with different heating type on the chemical compositions of EOs may also be dependent on the oringal characteristics of the raw materials.

Generally, the amount of oxygenated compounds was directly related to the economic value of the aromatice products as these substances were considered more influential on the aroma of EOs than other compenents 35 . However, there are more and more evidence proving that natural terpenes especially sesquiterpenes displayed excellently as antimicrobial 36 , antitumor, antiinflammatory, antiviral and antioxidant effects 37. Maybe economic valuation of the EOs should becomes to consider bioactivities as an important evaluation index. In conclusion, SFME could be an appropriate method to extract $P L$ fruit EO, as the obtained sample possessed higher contents of terpenes and oxidated compounds.

\subsection{Chemical compositon of hydrosols}

Hydrosols, which have been commercially used in many industries, were dominated by a wide range of functional compounds, including aldehydes, alcohols 38, phenols 39.40 and esters. GC-MS analysis displayed qualitative and quantitative discrepancies in the components of the two aqueous samples isolated from PL fruit of SFME and HD process. 59 components in SFME hydrosol, more than 32 in HD hydrosol were characterized, representing $95.65 \%$ and $93.97 \%$ of the total sample, respectively. Among these identified compounds of SFME and HD hydrosols, eugenol was found to be the most aboundant ( $25.44 \%$ and $22.82 \%$, respectively), followed by linalool ( $14.10 \%$ and $22.37 \%$, respectively). Trans-isoeugenol only consisted in the SFME hydrosol and took up $14.33 \%$ of the total chromatogram area. Additionally, there were other primary components presented in both hydrosols obtained by SFME and HD, including piperonal (7.28\% and 9.79\%), methyl-3-phenylpropanoate (6.73\% and 3.77\%), phenylethyl alcohol (3.36\% and $0.70 \%)$, a-terpineol (2.25\% and 1.97\%), trans-linalool oxide (1.39\% and 1.53\%), 3,4-dimethyl-3- cyclohexenecarbaldehyde (1.27\% and $2.04 \%$ ), and benzaldehyde (0.67\% and $1.23 \%$ ). Ethyl-3-phenylpropionate (1.05\%) was detected in SFME

Page $7 / 20$ 
hydrosol and was reported as a volatile flavor compound occurring in muskmelon and red fermented soybean curds. Eugenol and trans-isoeugenol were two important aromatic compounds with a spicy and clove-like scent. High amount of these two compounds are beneficial because of their antioxidant, antibacterial, antiantifungal, anticholinergic, and antidiabetic effects 41 . Eugenol (64.6 $\sim 120 \mathrm{mg} / \mathrm{kg}$ ) was firstly detected in $P L$ fruit by a new technology based on gas chromatography-high resolution mass spectrometry (GC-HRMS-Q-Orbitrap) 21. In our study, trans-isoeugenol was observed for the first time in $P L$ fruit but it was not sure that wether it was naturally biosynthesized in vivo or transformed from eugenol with the energy provided by microwave irradiation as eugenol was an intermediate to chemically synthesize trans-isoeugenol. Linalool, a diterpenoid, also can enhance the applying value of the products as it demonstrates to hold a broad spectrum of bioactive properties that can be exploited by the aromatherapies and comestic, pharmaceutical and food industries in the production of herbal-based health products 42 . Hydrosol collected during HD process contained furfural (4.62\%), 2-ethylhexanol (1.78\%), and acetophenone (1.06\%) as its primary constituents. In conclusion, phenols and alcohols were two predominate compounds of the hydrosols isolated from $P L$ fruit. Wheras, piperitone and linalool oxide were two dominant constituents in the hydrosols of leaves and inflorescence from Piper chimonanthifolium Kunth, which also belonged to the Piperaceae family 43.

\subsection{Antioxidant activities of EOs and hydrosols}

Antioxidant properties play a critical role in many of EOs' commercial applications, which is due to their extension of products shelf life and protection of human health against oxidative stress involved disorders 19 . So it was indispensable to evulate antioxidant potential of the EOs and hydrosols obtained from SFME and HD methods to guide their practical applications. The results were summarized in Table 4 and Table 5, respectively.

Free radicals with high ractivities can induce a series of chain reactions harmful to organisms and all raw materials. Radicalscavenging methods are well known as classical and reliable chemical assays for the determination of antioxidant potential of natural products or synthetic compounds. DPPH and ABTS ${ }^{+}$radicals were employed in this part. In the DPPH test, the EO from SFME method exhibited significantly higher scavenging capacities $(p<0.05)$ than the sample from the HD process at each investigated concentration except $2 \mathrm{mg} / \mathrm{mL}$ (Table 4). The calculated $\mathrm{IC}_{50}$ value of the SFME EO to scavenge DPPH radical was $3.30 \mathrm{mg} / \mathrm{mL}$, and that value of HD EO was $5.90 \mathrm{mg} / \mathrm{mL}$, which was about 1.79 -fold greater. For ABTS ${ }^{\bullet+}$ scavenging, there were significant differences between four tested concentrations $(0.2,0.4,0.6,1.0 \mathrm{mg} / \mathrm{mL})$ of SFME and HD EOs. The IC $\mathrm{C}_{50}$ values for the two samples were $0.48 \mathrm{mg} / \mathrm{mL}$ and $0.56 \mathrm{mg} / \mathrm{mL}$, respectively. However, scavenging capacities of SFME and HD EOs were moderate when compared with the positive control BHT with 56.22 and $4.86 \mu \mathrm{g} / \mathrm{mL}$ as the $\mathrm{IC}_{50}$ values for DPPH and ABTS ${ }^{+}$ radicals scavenging, respectively (Table 6).

In reducing antioxidant power assessment, bioactive compounds reduce ferric ions $\left(\mathrm{Fe}^{3+}\right)$ to the ferrous $\left(\mathrm{Fe}^{2+}\right)$, which then reacts with ferric chloride to form a colored complex having a maximum absorption at 700nm. More of the absorbing complex produced, higher absorbance values were presented, which indicated higher reductive capabilities and antioxidant potential of the tested samples. As shown in Table 4, the reducing abilities of the tested samples significantly increased with concentration increasing and the absorbance of the two EOs exhibited at the same concentration were significantly different $(p<0.05)$. When the concentration of SFME and HD EOs researched $10 \mathrm{mg} / \mathrm{mL}$, the absorbance were $0.5530 \pm 0.0141$ and $0.4610 \pm 0.0127$, respectively. Total phenolic content of SFME EO was $3.14 \pm 0.12 \mathrm{mg} \mathrm{GAE} / \mathrm{g}$, which was a little higher than $2.99 \pm 0.02$ of HD EO. Absorbance value of the positive control BHT was $0.8740 \pm 0.0325$ at a concentration of $60 \mu \mathrm{g} / \mathrm{mL}$, significantly higher than those former two. It had been proved that the reducing properties was positively related with the content of phenolic compounds due to their reactive hydroxyl, which can provide hydrogen ions to neutralize perxoyl radicals 44 . Furthermore, modest content in unsaturated terpenes, especially the components containing a carbon skeleton of cyclohexane-1,4-diene, could also contribute to good antioxidant behavior of EOs 19.

Total phenolic content of SFME hydrosol was $82.66 \pm 0.147 \mu \mathrm{g} \mathrm{GAE} / \mathrm{mL}$, which was significantly higher than $36.40 \pm 0.06 \mu \mathrm{g}$ $\mathrm{GAE} / \mathrm{mL}$ of HD hydrosol. According to the results, both hydrosols exhibited dose-dependent antioxidant activities and SFME hydrosol demonstrated to possess significantly stronger scavenging capacities of DPPH and ABTS ${ }^{+}$radicals, compared with the sample from HD method (Table 5, $p<0.05$ ). SFME hydrosol eliminated $93.93 \%$ of total DPPH radicals at the concentration of $40 \%$ and after that the scavenging capacity got a plateau, but the $\mathrm{HD}$ did $70.50 \%$ at the concentration of $100 \%$, relative to ascorbic acid with $93.23 \%$ inhibition at $8 \mu \mathrm{g} / \mathrm{mL}$. For $\mathrm{ABTS}^{+}$radical assay, the $\mathrm{IC}_{50}$ value of SFME hydrosol was $5.53 \%$, which was significantly

Page $8 / 20$ 
lower than $12.43 \%$ of $\mathrm{HD}$ hydrosol. The half maximal inhibitory concentration of ABTS radical for ascorbic acid was $3.14 \mu \mathrm{g} / \mathrm{mL}$ (Table 7). The reducing capabilities of the both hydrosols were observed to be significantly higher when compared with that of ascorbic acid at the concentration of $10 \mu \mathrm{g} / \mathrm{mL}$ while SFME sample demonstrated a wonderfully higher reducing ability $\left(A_{700}\right.$ $n m=1.3881)$ than ascorbic acid acted at the concentration of $80 \mu \mathrm{g} / \mathrm{ml}\left(A_{700 \mathrm{~nm}}=0.8530\right)$. The lower antioxidant activities by HD hydrosol displayed may be attributed to its lower phenolic content in keeping with the aforementioned opinon that phenolic compounds, including both terpenoids and phenylpropanoids, play an important role in antioxidant activities. However, all of the six hydrosols from different parts of arecanut and coconut showed weaker reducing power and $\mathrm{ABTS}^{+}$radical scavenging capacities compared with ascorbic acid at $5 \mu \mathrm{g} / \mathrm{mL} 22$.

\section{Conclusion}

In the present study, solvent-free microwave extraction (SFME) of EO from PL fruit was optimized with BBD of RSM for the first time. And hydrosols collected during SFME operation as a by-product was also explored for the first time. A much higher EO yield $0.747 \%$ was obtained under the optimal conditions, compared to that of HD approach $0.496 \%$. PL fruit EO obtained by SFME revealed higher contents of terpenes and oxygenated components. Additionally, it possessed stronger radical scavenging activities and reducing power compared with that obtained by traditional HD. Hydrosol collected during SFME process contained more constituents and exhibited more considerable antioxidant capacities than the hydrosol sample from HD. These results proposed that SFME was more effective and environment-friendly approach for the simultaneous extraction of EO and hydrosol from $P L$ fruit. Furthermore, in view of the potential as antioxidant, EO and hydrosol of $P L$ fruit can be recommended as natural supplements in daily chemical products and foods. However, further research is needed to establish these aromatic products as inhibitory of microorganism growth to develop their applied value.

\section{Declarations}

\section{Acknowledgements}

The authors thank the financial support by Hainan Major Research Project for Science and Technology (ZDKJ201817) and the National Nonprofit Institute Research Grant of CATAS-ITBB

(1630152020007 and 1630152017017).

\section{Author contributions}

Chen and Qin wrote the main manuscript text. Tang did optimization of SFME. Song did hydrodistillation. Huang and Liu did the evaluation of antioxidant activities of EOs and hydrosols. All authors reviewes the manuscript.

\section{Competing interests}

The author(s) declare no competing interests.

\section{Corresponding author}

Correspondence to Hua Chen.

\section{References}

1. Guo, Z. et al. Anti-inflammatory and antitumour activity of various extracts and compounds from the fruits of Piper longum L. Pharma. Pharmacol. 71, 1162-1171 (2019).

2. Zaveri, M., Khandhar, A., Patel, S. \& Patel, A. Chemistry and pharmacology of Piper Longum L.. Internat J Pharma Sci Rev Res. 5, 67-76 (2010).

3. Reddy, N. J., Vali, D. N., Rani, M. \& Rani, S. S. Evaluation of antioxidant, antibacterial and cytotoxic effects of green synthesized silver nanoparticles by Piper longum fruit. Mater. Sci. Engin.: C. 34, 115-122 (2014). 
4. Sunila, E. S. \& Kuttan, G. Immunomodulatory and antitumor activity of Piper longum Linn. and piperine. J Ethnopharmacol. 90, 339-346 (2004).

5. Li, K. et al. Qualitative and quantitative analysis of an alkaloid fraction from Piper longum L. using ultra-high performance liquid chromatography-diode array detector-electrospray ionization mass spectrometry. J Pharmaceut Biomed. 109, 28-35 (2015).

6. Kumar, S., Kamboj, J., Sharma, S. \& Suman \& Overview for various aspects of the health benefits of Piper Longum Linn. Fruit. $J$ Acupunct Merid Stud. 4, 134-140 (2011).

7. Koorse, K. G. et al. Anthelmintic Activity of Fruit Extract and Fractions of Piper longum L. In vitro.Pharmacognosy J10 (2018).

8. Das, J. et al. Isolation and characterization of antidermatophytic bioactive molecules from Piper longum L. leaves. Indian J Microbiol. 52, 624-629 (2012).

9. Kumar, A. et al. Antiinflammatory Activity of Piper longum Fruit Oil. Indian J Pharmaceut Sci. 71, 454-456 (2009).

10. Wang, H. et al. Protection effect of piperine and piperlonguminine from Piper longum L. alkaloids against rotenone-induced neuronal injury. Brain Res. 1639, 214-227 (2016).

11. Joseph, S. Hepatoprotective effect of aqueous extract of Piper longum and piperine when administered with anti-tubercular drugs. The Bioscan. 7, 661 (2012).

12. Noori, S., Zeynali, F. \& Almasi, H. Antimicrobial and antioxidant efficiency of nanoemulsion-based edible coating containing ginger (Zingiber officinale) essential oil and its effect on safety and quality attributes of chicken breast fillets. Food Cont. 84, 312-320 (2018).

13. Qian, H., Zhang, W., He, Y., Li, G. \& Shen, T. Chemical Composition, Antioxidant and Antimicrobial Activities of Essential Oil from Leontopodium longifolium Ling. J Essent Oil Bear Pl. 21, 175-180 (2018).

14. Bajalan, I., Rouzbahani, R., Pirbalouti, A. G. \& Maggi, F. Antioxidant and antibacterial activities of the essential oils obtained from seven Iranian populations of Rosmarinus officinalis. Indust Crops Prod. 107, 305-311 (2017).

15. Basak, S. \& Guha, P. Use of predictive model to describe sporicidal and cell viability efficacy of betel leaf (Piper betle L.) essential oil on Aspergillus flavus and Penicillium expansum and its antifungal activity in raw apple juice. LWT-Food Sci Technol. 80, 510-516 (2017).

16. Borges, R. S. et al. Anti-inflammatory and antialgic actions of a nanoemulsion of Rosmarinus officinalis L. essential oil and a molecular docking study of its major chemical constituents. Inflammopharmacology. 26, 183-195 (2018).

17. de Oliveira-Tintino, M. C. D. et al. Anti-inflammatory and anti-edematogenic action of the Croton campestris A. St.-Hil (Euphorbiaceae) essential oil and the compound $\beta$-caryophyllene in in vivo models. Phytomedicine. 41, 82-95 (2018).

18. Sirocchi, V. et al. Effect of Rosmarinus officinalis L. essential oil combined with different packaging conditions to extend the shelf life of refrigerated beef meat. Food Chem. 221, 1069-1076 (2017).

19. Amorati, R., Foti, M. C. \& Valgimigli, L. Antioxidant activity of essential oils. J Agricult Food Chem. 61, 10835-10847 (2013).

20. Abdel-Hameed, E. S. S., Salman, M. S., Fadl, M. A., Elkhateeb, A. \& Hassan, M. M. Chemical composition and biological activity of Mentha longifolia L. essential oil growing in Taif, KSA extracted by hydrodistillation, solvent free microwave and microwave hydrodistillation. J Essent Oil Bear PI. 21, 1-14 (2018).

21. Rivera-Pérez, A., López-Ruiz, R., Romero-González, R. \& Frenich, A. G. A new strategy based on gas chromatography-high resolution mass spectrometry (GC-HRMS-Q-Orbitrap) for the determination of alkenylbenzenes in pepper and its varieties. Food Chem. 321, 126727 (2020).

22. Shen, X. et al. Chemical composition, antibacterial and antioxidant activities of hydrosols from different parts of Areca catechu L. and Cocos nucifera L. Indust Crops Prod. 96, 110-119 (2017).

23. Blois, M. S. Antioxidant Determinations by the Use of a Stable Free Radical. Nature. 181, 1199-1200 (1958).

24. Re, R., Pellegrini, N., Pannala, A., Yang, A., Rice, E. C. \& M. \& Antioxidant activity applying an improved ABTS radical cation decolorization assay. Free Radic Biol Med. 26, 1231-1237 (1999).

25. Oyaizu, M. Studies on products of browning reaction. The Japan J Nutrit Dietet. 44, 307-315 (1986).

26. Liu, Z., Deng, B., Li, S. \& Zou, Z. Optimization of solvent-free microwave assisted extraction of essential oil from Cinnamomum camphora leaves. Indust Crops Prod. 124, 353-362 (2018).

Page 10/20 
27. Santos, J. D. C. et al. Chemical composition and antimicrobial activity of Satureja montana byproducts essential oils. Indust Crops Prod. 137, 541-548 (2019).

28. Lende, A. B. et al. Anti-inflammatory and analgesic activity of protocatechuic acid in rats and mice. Inflammopharmacology. 19, 255-263 (2011).

29. Supinya, T. et al. Fruit oil composition of Piper chaba Hunt., P. Iongum L. and P. nigrum L. J Essent Oil Res. 12, 603-608 (2000).

30. Liu, L., Song, G. \& Hu, Y. GC-MS analysis of the essential oils of Piper nigrum L. and Piper longum L. Chromatographia 66, 785-790(2007).

31. Adinew, B. GC-MS analysis of essential oil from long pepper growing in Tepi, south-west Ethiopia. Sci Technol Arts Res J. 3, 31 (2014).

32. Khalili, G., Mazloomifar, A., Larijani, K., Tehrani, M. S. \& Azar, P. A. Solvent-free microwave extraction of essential oils from Thymus vulgaris L. and Melissa officinalis L. Indust Crops Prod. 119, 214-217 (2018).

33. Qi, X. L. et al. Solvent-free microwave extraction of essential oil from pigeon pea leaves [Cajanus cajan (L.) Millsp.] and evaluation of its antimicrobial activity. Indust Crops Prod. 58, 322-328 (2014).

34. Wang, Z. et al. Improved solvent-free microwave extraction of essential oil from dried Cuminum cyminum L. and Zanthoxylum bungeanum Maxim. J Chromatogr A. 1102, 11-17 (2006).

35. Raut, J. S. \& Karuppayil, S. M. A status review on the medicinal properties of essential oils. Indust Crops Prod. 62, 250-264 (2014).

36. Tan, W. N. et al. Sesquiterpenes rich essential oil from Garcinia celebica L. and its cytotoxic and antimicrobial activities. Nat Prod Res. 34, 1-5 (2019).

37. Fu, J., Li, F. H., Li, C. K., Li, B. M. \& Kang, J. Reviews on natural monocyclic sesquiterpenoids and their bioactivities. China J Chin Mater Mater. 44, 3672-3683 (2019).

38. Traka, C. K., Petrakis, E. A., Kimbaris, A. C., Polissiou, M. G. \& Perdikis, D. C. Effects of Ocimum basilicum and Ruta chalepensis hydrosols on Aphis gossypii and Tetranychus urticae.J Appl Entomo/142 (2018).

39. Francezon, N. \& Stevanovic, T. Chemical composition of essential oil and hydrosol from Picea mariana bark residue. Bioresources. 12, 2635-2645 (2017).

40. Tornuk, F. et al. Efficacy of various plant hydrosols as natural food sanitizers in reducing Escherichia coli 0157:H7 and Salmonella Typhimurium on fresh cut carrots and apples. Int J Food Microbiol. 148, 30-35 (2011).

41. Topal, F. Anticholinergic and antidiabetic effects of isoeugenol from clove (Eugenia caryophylata) oil. Int J Food Prop. 22, 583-592 (2019).

42. Pereira, I., Severino, P., Santos, A. C., Silva, A. M. \& Souto, E. B. Linalool bioactive properties and potential applicability in drug delivery systems. Coll Surf B: Biointerf. 171, 566-578 (2018).

43. Davod, Y. et al. Biochemical activities of Iranian Mentha piperita L. and Myrtus communis L. essential oils. Phytochem. 67, 1249-1255 (2006).

44. Lee, Y. R., Woo, K. S., Kim, K. J., Son, J. R. \& Jeong, H. S. Antioxidant activities of ethanol extracts from germinated specialty rough rice. Food Sci Biotechnol. 16, 765-770 (2007).

\section{Tables}

Table 1 Box-Behnken design with experimental values and predicted values for PL EO yield (\%) 


\begin{tabular}{|c|c|c|c|c|c|}
\hline \multirow[t]{2}{*}{ Runs } & \multirow{2}{*}{$\begin{array}{l}\text { Microwave Irradiation } \\
\text { Power } \\
\left(X_{1}, W\right)\end{array}$} & \multirow{2}{*}{$\begin{array}{l}\text { Microwave Irradiation Time } \\
\left(X_{2}, \min \right)\end{array}$} & \multirow{2}{*}{$\begin{array}{l}\text { Percentage Humidity of the } \\
\text { Matrix }\left(X_{3}, \%\right)\end{array}$} & \multicolumn{2}{|c|}{ Yield $(\%, W / W)$} \\
\hline & & & & $\begin{array}{l}\text { Actual } \\
\text { value }\end{array}$ & $\begin{array}{l}\text { Predicted } \\
\text { value }\end{array}$ \\
\hline 1 & $300(-1)$ & $20(-1)$ & $60(0)$ & 0.147 & 0.14 \\
\hline 2 & $600(1)$ & 20 & 60 & 0.496 & 0.51 \\
\hline 3 & 300 & $40(1)$ & 60 & 0.334 & 0.32 \\
\hline 4 & 600 & 40 & 60 & 0.733 & 0.74 \\
\hline 5 & 300 & $30(0)$ & $50(-1)$ & 0.163 & 0.16 \\
\hline 6 & 600 & 30 & 50 & 0.666 & 0.66 \\
\hline 7 & 300 & 30 & $70(1)$ & 0.314 & 0.32 \\
\hline 8 & 600 & 30 & 70 & 0.610 & 0.61 \\
\hline 9 & $450(0)$ & 20 & 50 & 0.359 & 0.36 \\
\hline 10 & 450 & 40 & 50 & 0.554 & 0.56 \\
\hline 11 & 450 & 20 & 70 & 0.423 & 0.41 \\
\hline 12 & 450 & 40 & 70 & 0.622 & 0.62 \\
\hline 13 & 450 & 30 & 60 & 0.644 & 0.63 \\
\hline 14 & 450 & 30 & 60 & 0.632 & 0.63 \\
\hline 15 & 450 & 30 & 60 & 0.637 & 0.63 \\
\hline 16 & 450 & 30 & 60 & 0.624 & 0.63 \\
\hline 17 & 450 & 30 & 60 & 0.621 & 0.63 \\
\hline
\end{tabular}

Table 2 Analysis of variance (ANOVA) for the experimental results. ${ }^{a}$ 


\begin{tabular}{|c|c|c|c|c|c|}
\hline Source & Sum of Squares & $\begin{array}{l}\text { Degree of } \\
\text { freedom }\end{array}$ & Mean Square & F Value & $\mathrm{p}$-value \\
\hline Model $^{b}$ & 0.5200 & 9 & 0.0580 & 424.08 & $<0.0001^{\star \star \star}$ \\
\hline$x_{1}$ & 0.3000 & 1 & 0.3000 & 2181.25 & $<0.0001^{\star \star \star}$ \\
\hline$x_{2}$ & 0.0840 & 1 & 0.0840 & 610.07 & $<0.0001^{\star \star \star}$ \\
\hline$x_{3}$ & 0.0064 & 1 & 0.0064 & 46.95 & $0.0002^{\star \star \star}$ \\
\hline$x_{1} x_{2}$ & 0.0006 & 1 & 0.0006 & 4.61 & 0.0689 \\
\hline$x_{1} x_{3}$ & 0.0110 & 1 & 0.0110 & 78.08 & $<0.0001^{\star \star \star}$ \\
\hline$x_{2} x_{3}$ & 0.0000 & 1 & 0.0000 & 0.029 & 0.8693 \\
\hline$x 21$ & 0.0690 & 1 & 0.0690 & 499.97 & $<0.0001^{\star * \star}$ \\
\hline$x 22$ & 0.0250 & 1 & 0.0250 & 179.07 & $<0.0001^{\star \star \star}$ \\
\hline$x 23$ & 0.0180 & 1 & 0.0180 & 132.52 & $<0.0001^{\star \star \star}$ \\
\hline Residual & 0.0010 & 7 & 0.0001 & & \\
\hline Lack of Fit & 0.0006 & 3 & 0.0002 & 2.29 & 0.22 \\
\hline Pure Error & 0.0004 & 4 & 0.0001 & & \\
\hline Cor Total ${ }^{\mathrm{c}}$ & 0.5200 & 16 & & & \\
\hline \multicolumn{6}{|c|}{ Credibility analysis of the regression equations } \\
\hline Std. Dev. ${ }^{d}$ & Mean C.V. ${ }^{\text {e } \%}$ & Press & Adj & Predicted $\mathrm{R}^{2}$ & Adequacy precision \\
\hline 0.012 & 2.32 & 0.01 & $0.9982 \quad 0.9 c$ & 0.9804 & 65.83 \\
\hline
\end{tabular}

a The results were obtained with Design Expert 8.0.6 software.

${ }^{\mathrm{b}} X_{1}$ is is microwave irradiation power $(\mathrm{W}), X_{2}$ is microwave irradiation time $(\mathrm{min}), X_{3}$ is Percentage Humidity of the Matrix (\%).

${ }^{\mathrm{c}}$ Totals of all information corrected for the mean.

d Standard deviation.

${ }^{\mathrm{e}}$ Coefficient of variation.

${ }^{*} p<0.05$, significant.

${ }^{* *} p<0.01$, highly significant.

${ }^{* * *} p<0.001$, extremely significant.

Table 3 Identification of constituents by GC-MS of $P L$ fruit EOs and hydrosols extracted by SFME and HD methods 


\begin{tabular}{|c|c|c|c|c|c|c|c|}
\hline & EOs & & & Hydroso & & & \\
\hline R.T. & & $\mathrm{HD}$ & SFME & R.T. & & $\mathrm{HD}$ & SFME \\
\hline 13.436 & 3-Carene & 0.16 & 0.13 & 2.913 & Pyridine & 5.41 & 1.02 \\
\hline 20.016 & (E)-5-Tridecene & 0.11 & 0.22 & 4.366 & Methyl- pyrazine & - & 0.31 \\
\hline 20.44 & Tridecane & 0.53 & 0.83 & 3.971 & $\begin{array}{l}\text { 2-Methyltetrahydro-3- } \\
\text { furanone }\end{array}$ & 0.38 & - \\
\hline 21.67 & $\delta$-elemene & 1.66 & 0.18 & 4.607 & 3,4-Dimethyl pyrazole & - & 0.39 \\
\hline 22.065 & a-Cubebene & - & 0.07 & 4.595 & Furfural & 4.62 & - \\
\hline 22.917 & a-Copaene & 0.30 & 0.50 & 5.476 & $p$-Xylene & 0.68 & 0.14 \\
\hline 23.941 & a-bergamotene & 1.27 & 1.85 & 6.089 & Styrene & 0.38 & 0.11 \\
\hline 24.405 & $\beta$-Caryophyllene & 8.57 & 10.65 & 6.655 & $\begin{array}{l}\text { 2-Methyl-2-cyclopenten-1- } \\
\text { one }\end{array}$ & - & 0.07 \\
\hline 23.461 & $\beta$-elemene & - & 2.40 & 8.349 & Benzaldehyde & 1.23 & 0.67 \\
\hline 25.389 & Humulene & 5.64 & 6.91 & 9.768 & 2-ethyl-6-methyl-Pyrazine & - & 0.10 \\
\hline 24.611 & (+)-epi-Bicyclosesquiphellandrene & - & 0.12 & 10.483 & 1,3-Diazine & - & 0.31 \\
\hline 25.509 & $(E)$ - $\beta$-Famesene & 1.97 & 2.06 & 10.832 & Eucalyptol & - & 0.22 \\
\hline 26.11 & Y-Muurolene & 0.17 & 0.45 & 10.884 & 2-Ethylhexanol & 1.78 & - \\
\hline 26.253 & Germacrene D & 11.70 & 9.67 & 11.135 & Benzyl alcohol & - & 0.30 \\
\hline 26.459 & $\beta$-selinene & 5.28 & 5.05 & 11.313 & Benzeneacetaldehyde & - & 0.64 \\
\hline 26.762 & Zingiberene & 6.60 & 5.66 & 12.137 & Acetophenone & 1.06 & 0.48 \\
\hline 26.579 & $( \pm)$ - $\beta$-Cadinene & - & 0.23 & 12.383 & $\begin{array}{l}\text { cis-Linalool oxide } \\
\text { (furanoid) }\end{array}$ & 0.93 & 0.52 \\
\hline 26.934 & Pentadecane & 9.39 & 7.31 & 12.955 & $\begin{array}{l}\text { trans-Linalool oxide } \\
\text { (furanoid) }\end{array}$ & 1.53 & 1.39 \\
\hline 27.191 & $\beta$-Bisabolene & 6.85 & 6.57 & 13.447 & Linalool & 22.37 & 14.10 \\
\hline 27.403 & (-)- a-Panasinsen & 2.23 & 2.59 & 13.516 & Limonene & - & 0.11 \\
\hline 27.54 & $\delta$-Cadinene & 1.07 & 1.49 & 13.659 & $\begin{array}{l}1,2,4,4- \\
\text { Tetramethylcyclopentene }\end{array}$ & - & 0.20 \\
\hline 28.101 & Ocimene & 3.12 & 2.85 & 13.922 & Phenylethyl Alcohol & 0.70 & 3.36 \\
\hline 28.45 & a-ylangene & 0.20 & 0.31 & 14.506 & $\begin{array}{l}\text { 4-Acetyl-1- } \\
\text { methylcyclohexene }\end{array}$ & - & 0.17 \\
\hline 29.12 & 9,10-Dehydro- Isolongifolene & 0.16 & 0.22 & 14.935 & (+)-2-Bornanone & 0.57 & 0.44 \\
\hline 29.32 & Caryophyllene oxide & 1.77 & 2.51 & 15.393 & Isoborneol & - & 0.15 \\
\hline 29.503 & a-Cedrene & 0.32 & 0.34 & 15.656 & Benzenepropanal & - & 0.15 \\
\hline 30.024 & endo-2-Methylbicyclo[3.3.1]nonane & 0.67 & 1.26 & 15.73 & endo-Borneol & 0.81 & 0.64 \\
\hline 30.133 & $\beta$-Humulene & 0.12 & 0.41 & 15.896 & $\begin{array}{l}\text { 2,2,6-Trimethyl-6- } \\
\text { ethenyltetrahydro-2H- } \\
\text { pyran-3-ol }\end{array}$ & - & 0.22 \\
\hline 30.894 & Alloaromadendrene & 0.27 & - & 16.005 & Menthol & 0.64 & 0.44 \\
\hline 30.287 & a-gurjunene & - & 0.22 & 16.148 & Terpinen-4-ol & - & 0.73 \\
\hline
\end{tabular}




\begin{tabular}{|c|c|c|c|c|c|c|c|}
\hline 30.602 & Spathulenol & 0.26 & 0.79 & 16.485 & $\begin{array}{l}\text { 1-methyl-4-(1- } \\
\text { methylethenyl)-Benzene }\end{array}$ & - & 0.27 \\
\hline 30.951 & $\begin{array}{l}\text { Bicyclo[4.4.0]dec-1-ene,2-isopropyl-5- } \\
\text { methyl-9-methylene }\end{array}$ & - & 0.27 & 16.651 & a-Terpineol & 1.97 & 2.25 \\
\hline 31.082 & Y-Muurolene & - & 0.24 & 16.875 & trans-Dihydrocarvone & - & 0.07 \\
\hline 31.3 & Epizonarene & - & 0.72 & 18.099 & cis-Geraniol & - & 0.22 \\
\hline 31.403 & $(+)-\gamma$-Maaliene & 0.11 & 0.30 & 18.213 & 3-Phenylpropanol & 0.36 & 0.89 \\
\hline 31.803 & Musk Ambrette & 0.43 & - & 18.385 & 4-Isopropylbenzaldehyde & - & 0.50 \\
\hline 31.964 & (Z)-3-Heptadecene & 6.45 & 4.24 & 18.534 & D-Carvone & - & 0.23 \\
\hline 32.049 & 1,13-Tridecadiene & 0.30 & 0.28 & 19.055 & 4-(2-propenyl)-Phenol & - & 0.50 \\
\hline 31.992 & 8-Heptadecene & 10.29 & 6.75 & 19.501 & trans-Cinnamaldehyde & - & 1.03 \\
\hline 32.061 & 1,13-Tetradecadiene & 0.13 & 0.13 & 19.615 & $\begin{array}{l}\text { methyl 3- } \\
\text { phenylpropanoate }\end{array}$ & 3.77 & 6.73 \\
\hline 32.604 & Heptadecane & 7.77 & 4.83 & 19.942 & cis-Anethol & 0.62 & 0.34 \\
\hline 33.171 & $\begin{array}{l}\text { 6-Isopropenyl-4,8a-dimethyl-1,2,3, } \\
5,6,7,8,8 \text { a-octahydro-naphthalen-2- } \\
\text { ol }\end{array}$ & - & 0.10 & 21.549 & Piperonal & 9.79 & 7.28 \\
\hline 37.142 & 9-Nonadecene & 0.76 & 0.62 & 22.064 & Ethyl 3-phenylpropionate & - & 1.05 \\
\hline 37.148 & Z-5-Nonadecene & 1.40 & 1.12 & 22.419 & Eugenol & 22.82 & 25.44 \\
\hline 37.691 & Nonadecane & 0.49 & 0.44 & 22.802 & trans-Isoeugenol & - & 14.33 \\
\hline 37.01 & $\begin{array}{l}\text { 1-(1,5-dimethyl-4-hexenyl)-4- } \\
\text { methylbenzene }\end{array}$ & - & 0.08 & 23.93 & Methyleugenol & 0.46 & 0.47 \\
\hline 40.587 & Octadecanal & - & 0.07 & 26.791 & Pentadecane & - & 0.10 \\
\hline 42.051 & Cyclohexadecane & - & 0.12 & 27.512 & Myristicin & - & 0.07 \\
\hline 42.28 & $\begin{array}{l}\text { 9,12-Octadecadienoic acid (Z,Z)-methyl } \\
\text { ester }\end{array}$ & - & 0.06 & 28.559 & Elemicin & 0.47 & 0.27 \\
\hline 42.4 & Heneicosane & - & 0.11 & 29.114 & $\begin{array}{l}\text { 9,10-dehydro- } \\
\text { Cycloisolongifolene }\end{array}$ & 0.50 & - \\
\hline 42.715 & 3,7,11,15-Tetramethyl-2-hexadecen-1-ol & - & 0.05 & 30.024 & $\begin{array}{l}\text { 3,4-Dimethyl-3- } \\
\text { cyclohexenecarbaldehyde }\end{array}$ & 2.04 & 1.27 \\
\hline \multirow[t]{11}{*}{51.664} & Bis-(2-ethylhexyl) phthalate & - & 1.61 & 30.127 & $\beta$-Humulene & 0.57 & 0.21 \\
\hline & Hydrocarbon compounds & 96.06 & 90.8 & 30.293 & Aromandendrene & - & 0.19 \\
\hline & Oxygenated compounds & 2.46 & 5.19 & 30.596 & $\begin{array}{l}\text { 8,9-dehydro- } \\
\text { Cycloisolongifolene }\end{array}$ & 1.94 & - \\
\hline & Monoterpene hydrocarbons & 3.28 & 2.98 & 30.476 & (-)-Alloaromadendrene & - & 0.15 \\
\hline & Aliphatic hydrocarbons & 38.29 & 28.34 & 30.596 & Espatulenol & - & 0.70 \\
\hline & Sesquiterpene hydrocarbons & 54.49 & 59.48 & 30.676 & $\beta$-Guaiene & - & 0.28 \\
\hline & Oxygenated sesquiterpenes & 2.03 & 3.40 & 30.962 & Longipinene & - & 0.30 \\
\hline & Others & 0.43 & 1.79 & 31.105 & cis-Thujopsene & 0.47 & 0.17 \\
\hline & \multirow[t]{3}{*}{ Total } & 98.52 & 95.99 & 31.191 & Cuparene & - & 0.16 \\
\hline & & & & 31.305 & Eremophilene & 2.04 & 0.68 \\
\hline & & & & 31.408 & 2-Isopropyl-5-methyl-9- & - & 0.42 \\
\hline
\end{tabular}

Page 15/20 


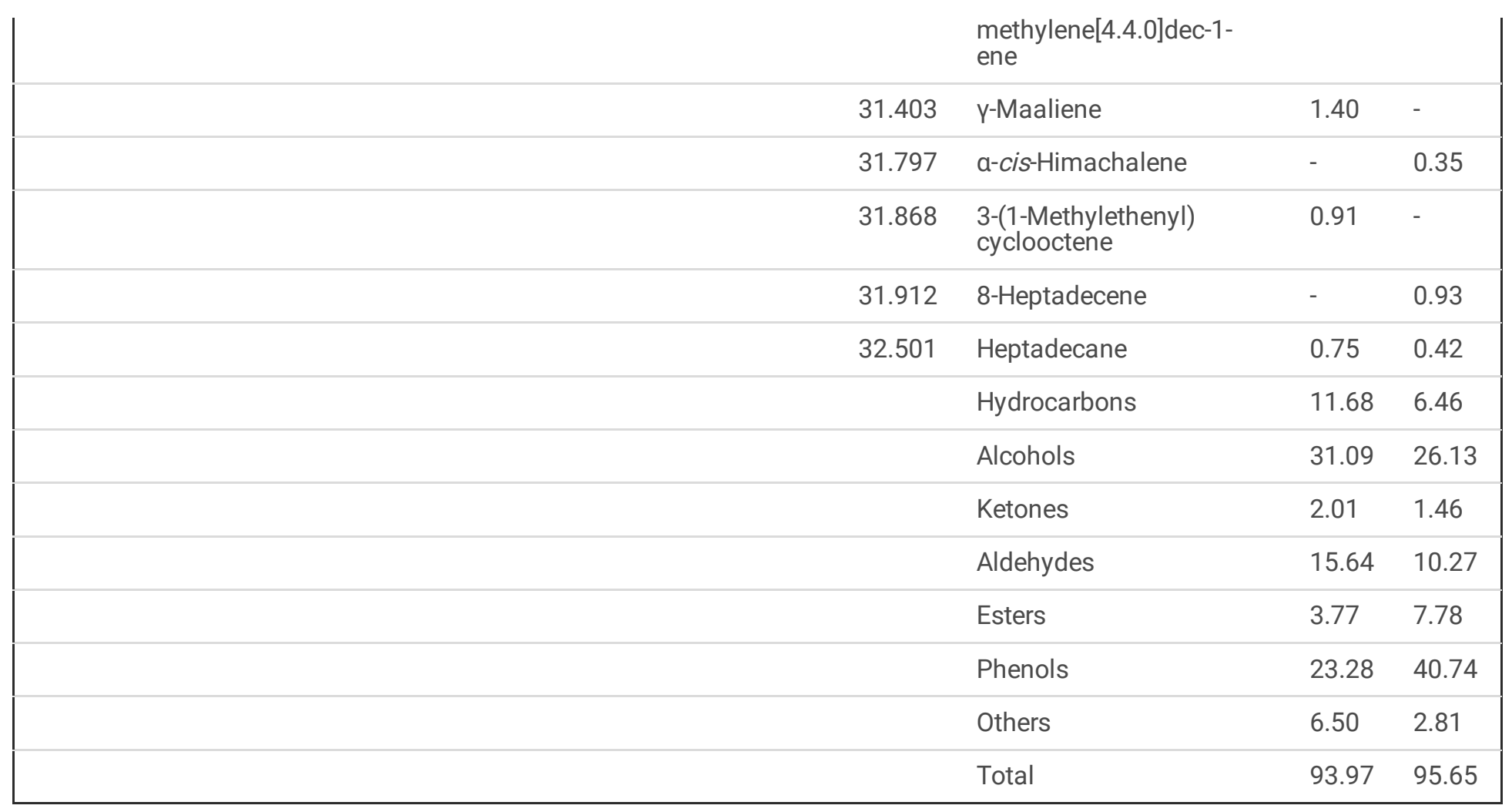

Table 4 Antioxidant activities of $P L$ fruit EOs in DPPH•, ABTS ${ }^{\bullet+}$ and reducing power assays

\begin{tabular}{|c|c|c|c|c|c|c|}
\hline \multirow{3}{*}{$\begin{array}{l}\text { Sample } \\
\text { Concentration } \\
(\mathrm{mg} / \mathrm{mL})\end{array}$} & \multicolumn{2}{|c|}{$\begin{array}{l}\text { DPPH Scavenging activity } \\
\text { (Inhibition Rate, \%) }\end{array}$} & \multicolumn{2}{|c|}{$\begin{array}{l}\text { ABTS }{ }^{\bullet+} \text { Scavenging activity } \\
\text { (Inhibition Rate, \%) }\end{array}$} & \multicolumn{2}{|l|}{$\begin{array}{l}\text { Reducing Power } \\
\text { (Absorbance) }\end{array}$} \\
\hline & SPME & $\mathrm{HD}$ & SPME & $\mathrm{HD}$ & SPME & $\mathrm{HD}$ \\
\hline & $\begin{array}{l}\mathrm{IC}_{50}=3.30 \\
\mathrm{mg} / \mathrm{mL}\end{array}$ & $\begin{array}{l}\mathrm{IC}_{50}=5.90 \\
\mathrm{mg} / \mathrm{mL}\end{array}$ & $\begin{array}{l}\mathrm{IC}_{50}=0.38 \\
\mathrm{mg} / \mathrm{mL}\end{array}$ & $\mathrm{IC}_{50}=0.37 \mathrm{mg} / \mathrm{mL}$ & & \\
\hline 0.1 & - & - & $17.51 \pm 1.03^{\mathrm{a}}$ & $15.24 \pm 0.68^{a}$ & - & - \\
\hline 0.2 & - & - & $31.77 \pm 2.52^{c}$ & $22.04 \pm 1.14^{b}$ & - & - \\
\hline 0.4 & - & - & $51.54 \pm 2.06^{\mathrm{e}}$ & $41.49 \pm 1.15^{d}$ & - & - \\
\hline 0.6 & - & - & $62.88 \pm 2.06^{f}$ & $50.41 \pm 0.49^{e}$ & - & - \\
\hline 0.8 & - & - & $68.07 \pm 0.68^{g}$ & $70.34 \pm 0.23^{g}$ & - & - \\
\hline 1 & $38.13 \pm 1.45^{\mathrm{b}}$ & $26.11 \pm 1.70^{a}$ & $82.01 \pm 2.52^{h}$ & $86.71 \pm 0.46^{i}$ & $0.2350 \pm 0.0057^{b c}$ & $0.2135 \pm 0.0149^{a}$ \\
\hline 2 & $41.08 \pm 1.27^{b}$ & $36.94 \pm 1.02^{b}$ & - & - & $0.2805 \pm 0.0078^{d}$ & $0.2415 \pm 0.0078^{c}$ \\
\hline 4 & $56.36 \pm 1.45^{\mathrm{cd}}$ & $52.83 \pm 3.74^{c}$ & - & - & $0.3635 \pm 0.0134^{e}$ & $0.3000 \pm 0.0170^{d}$ \\
\hline 6 & $66.12 \pm 0.36^{\mathrm{e}}$ & $54.03 \pm 3.14^{c}$ & - & - & $0.4310 \pm 0.0099^{f}$ & $0.3610 \pm 0.0184^{e}$ \\
\hline 8 & $72.28 \pm 0.73^{f}$ & $55.23 \pm 3.12^{c d}$ & - & - & $0.4960 \pm 0.0085^{\mathrm{h}}$ & $0.4130 \pm 0.0099^{f}$ \\
\hline 10 & $77.54 \pm 0.18^{f}$ & $59.45 \pm 0.51^{d}$ & - & - & $0.5530 \pm 0.0141^{i}$ & $0.4610 \pm 0.0127^{g}$ \\
\hline
\end{tabular}


Table 5 Antioxidant activities of hydrosols in $\mathrm{DPPH} \bullet, \mathrm{ABTS}^{\bullet+}$ and reducing power assays

\begin{tabular}{|c|c|c|c|c|c|c|}
\hline \multirow{2}{*}{$\begin{array}{l}\text { Sample } \\
\text { Concentration } \\
(\%)\end{array}$} & \multicolumn{2}{|c|}{$\begin{array}{l}\text { DPPH Scavenging activity } \\
\text { (Inhibition Rate, \%) }\end{array}$} & \multicolumn{2}{|c|}{$\begin{array}{l}\text { ABTS }^{\bullet+} \text { Scavenging activity } \\
\text { (Inhibition Rate, \%) }\end{array}$} & \multicolumn{2}{|l|}{$\begin{array}{l}\text { Reducing Power } \\
\text { (Absorbance) }\end{array}$} \\
\hline & $\begin{array}{l}\text { SPME- } \\
\text { Hydrosol } \\
\mathrm{IC}_{50}=6.31 \%\end{array}$ & $\begin{array}{l}\text { HD- Hydrosol } \\
\mathrm{IC}_{50}=49.57 \\
\%\end{array}$ & $\begin{array}{l}\text { SPME- } \\
\text { Hydrosol } \\
\mathrm{IC}_{50}=5.53 \%\end{array}$ & $\begin{array}{l}\text { HD- } \\
\text { Hydrosol } \\
\mathrm{IC}_{50}= \\
12.43 \%\end{array}$ & SPME- Hydrosol & HD- Hydrosol \\
\hline 2 & $17.42 \pm 0.79^{b}$ & $5.62 \pm 0.64^{a}$ & $20.33 \pm 1.05^{c}$ & $8.50 \pm 0.10^{a}$ & $0.0765 \pm 0.0078^{b c}$ & $0.0190 \pm 0.0018^{a}$ \\
\hline 4 & $37.53 \pm 0.64^{\mathrm{e}}$ & $10.90 \pm 0.48^{\mathrm{a}}$ & $36.80 \pm 1.68^{\mathrm{e}}$ & $17.74 \pm 0.21^{b}$ & $0.1120 \pm 0.0000^{\mathrm{cd}}$ & $0.0395 \pm 0.0078^{\mathrm{ab}}$ \\
\hline 6 & $48.43 \pm 0.16^{f}$ & $15.06 \pm 0.32^{\mathrm{a}}$ & $58.61 \pm 0.21^{\mathrm{g}}$ & $29.77 \pm 2.76^{d}$ & $0.1510 \pm 0.0014^{\mathrm{de}}$ & $0.0570 \pm 0.0017^{\mathrm{ab}}$ \\
\hline 8 & $60.67 \pm 0.95^{\mathrm{g}}$ & $17.42 \pm 1.75^{b}$ & $72.70 \pm 0.42^{h}$ & $39.70 \pm 1.06^{\mathrm{e}}$ & $0.1890 \pm 0.0042^{\mathrm{e}}$ & $0.0665 \pm 0.0086^{b}$ \\
\hline 10 & $75.28 \pm 0.64^{i}$ & $21.12 \pm 1.59^{c}$ & $79.53 \pm 0.42^{i}$ & $45.86 \pm 0.43^{f}$ & $0.2435 \pm 0.0092^{f}$ & $0.0695 \pm 0.0064^{b}$ \\
\hline 20 & $88.65 \pm 1.43^{i}$ & $31.20 \pm 0.06^{d}$ & $98.22 \pm 0.00^{k}$ & $72.63 \pm 2.98^{h}$ & $0.4335 \pm 0.0120^{h}$ & $0.1195 \pm 0.0050^{d}$ \\
\hline 40 & $93.93 \pm 0.32^{j}$ & $47.98 \pm 0.79^{f}$ & $98.37 \pm 0.21^{k}$ & $91.28 \pm 0.43^{j}$ & $0.7150 \pm 0.0141^{i}$ & $0.1755 \pm 0.0162^{\mathrm{e}}$ \\
\hline 60 & $93.70 \pm 0.00^{j}$ & $62.70 \pm 2.54^{\mathrm{g}}$ & $98.66 \pm 0.21^{k}$ & $98.20 \pm 0.00^{k}$ & $0.9995 \pm 0.0375^{j}$ & $0.2695 \pm 0.0035^{f}$ \\
\hline 80 & $93.70 \pm 0.00^{j}$ & $66.85 \pm 1.11^{h}$ & $98.81 \pm 0.00^{\mathrm{k}}$ & $98.50 \pm 0.00^{k}$ & $1.2250 \pm 0.0481^{k}$ & $0.3315 \pm 0.0021^{g}$ \\
\hline 100 & $93.70 \pm 0.00^{j}$ & $70.50 \pm 0.16^{i}$ & $98.81 \pm 0.00^{k}$ & $98.80 \pm 0.00^{k}$ & $1.3881 \pm 0.1250^{l}$ & $0.3960 \pm 0.0063^{h}$ \\
\hline
\end{tabular}

Table 6 Antioxidant activities of BHT in DPPH, ABTS ${ }^{\bullet+}$ and reducing power assays

\begin{tabular}{|llll|}
\hline $\begin{array}{l}\text { Concentration of } \\
(\mu \mathrm{gH} / \mathrm{mL})\end{array}$ & $\begin{array}{l}\mathrm{DPPH} \cdot \text { Scavenging activity } \\
\text { (Inhibition Rate, \%) } \\
\mathrm{IC}_{50}=56.22 \mu \mathrm{g} / \mathrm{mL}\end{array}$ & $\begin{array}{l}\mathrm{ABTS}{ }^{\bullet+} \text { Scavenging activity } \\
\text { (Inhibition Rate, \%) } \\
\mathrm{IC}_{50}=4.68 \mu \mathrm{g} / \mathrm{mL}\end{array}$ & $\begin{array}{l}\text { Reducing Power } \\
\text { (Absorbance) }\end{array}$ \\
\hline 4 & $10.34 \pm 1.14$ & $34.59 \pm 3.57$ & $0.0467 \pm 0.0037$ \\
\hline 6 & $15.40 \pm 1.31$ & $44.23 \pm 4.40$ & $0.0575 \pm 0.0035$ \\
\hline 8 & $18.05 \pm 0.54$ & $51.03 \pm 3.96$ & $0.08454 \pm 0.0048$ \\
\hline 10 & $21.90 \pm 2.13$ & $70.69 \pm 2.89$ & $0.1055 \pm 0.0056$ \\
\hline 20 & $26.59 \pm 1.44$ & $80.52 \pm 4.93$ & $0.1452 \pm 0.0103$ \\
\hline 40 & $32.61 \pm 1.31$ & $95.01 \pm 1.97$ & $0.3205 \pm 0.0098$ \\
\hline 60 & $45.58 \pm 3.12$ & $96.12 \pm 2.23$ & $0.5940 \pm 0.0439$ \\
\hline 80 & $53.79 \pm 5.06$ & $96.45 \pm 5.66$ & $0.8425 \pm 0.0562$ \\
\hline 100 & $59.68 \pm 3.71$ & $96.33 \pm 2.19$ & $1.2245 \pm 0.0998$ \\
\hline
\end{tabular}


Table 7 Antioxidant activities of ascorbic acid in DPPH, $\mathrm{ABTS}^{\bullet+}$ and reducing power assays

\begin{tabular}{|lllll|}
\hline $\begin{array}{l}\text { Concentration of } \\
\text { ascorbic acid } \\
(\mu \mathrm{g} / \mathrm{mL})\end{array}$ & $\begin{array}{l}\mathrm{DPPH} \cdot \text { Scavenging activity } \\
(\text { Inhibition Rate, } \%)\end{array}$ & $\begin{array}{l}\mathrm{ABTS}{ }^{\bullet+} \text { Scavenging activity } \\
(\text { Inhibition Rate, })\end{array}$ & $\begin{array}{l}\text { Concentration of } \\
\text { ascorbic acid }\end{array}$ & $\begin{array}{l}\text { Reducing Power } \\
\text { (Absorbance) }\end{array}$ \\
\hline 0.2 & 0 & $\mathrm{IC}_{50}=3.14 \mu \mathrm{g} / \mathrm{mL}$ & 1 & \\
\hline 0.4 & $3.26 \pm 0.01$ & 2 & $0.0180 \pm 0.0003$ \\
\hline 0.6 & $1.92 \pm 0.02$ & $6.53 \pm 0.29$ & $0.0460 \pm 0.0015$ \\
\hline 0.8 & $3.95 \pm 0.06$ & $9.94 \pm 0.23$ & 4 & $0.1035 \pm 0.0078$ \\
\hline 1 & $6.20 \pm 0.07$ & $15.78 \pm 1.01$ & 6 & $0.1210 \pm 0.0056$ \\
\hline 2 & $10.26 \pm 0.16$ & $23.07 \pm 0.41$ & 10 & $0.2805 \pm 0.0123$ \\
\hline 4 & $27.51 \pm 0.47$ & $30.26 \pm 2.31$ & 20 & $0.4390 \pm 0.0254$ \\
\hline 6 & $54.56 \pm 1.23$ & $65.73 \pm 2.97$ & 40 & $0.6370 \pm 0.233$ \\
\hline 8 & $80.72 \pm 4.56$ & $90.50 \pm 4.45$ & 60 & $0.7545 \pm 0.0489$ \\
\hline
\end{tabular}

Figures

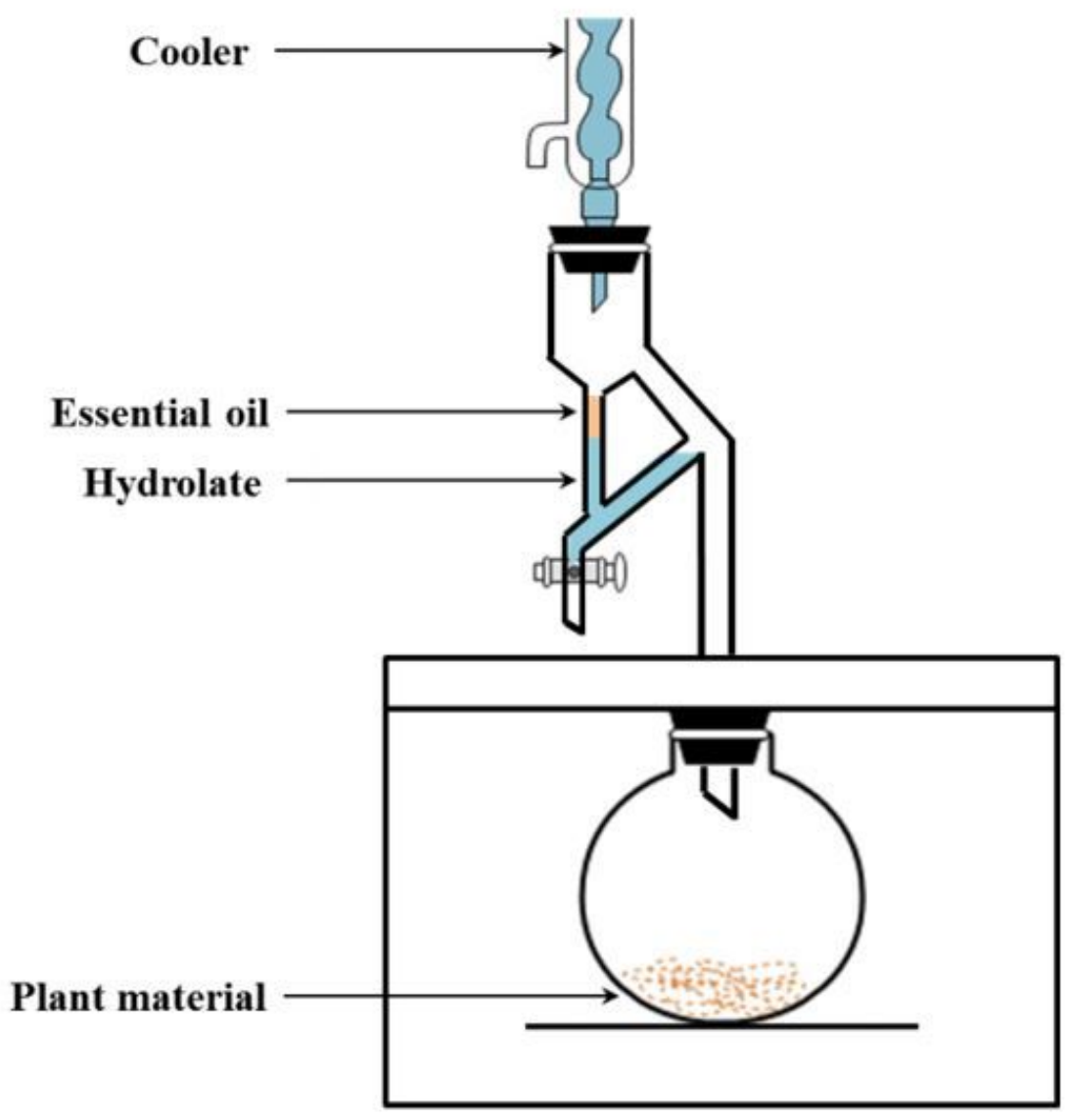

Microwave oven

Figure 1 


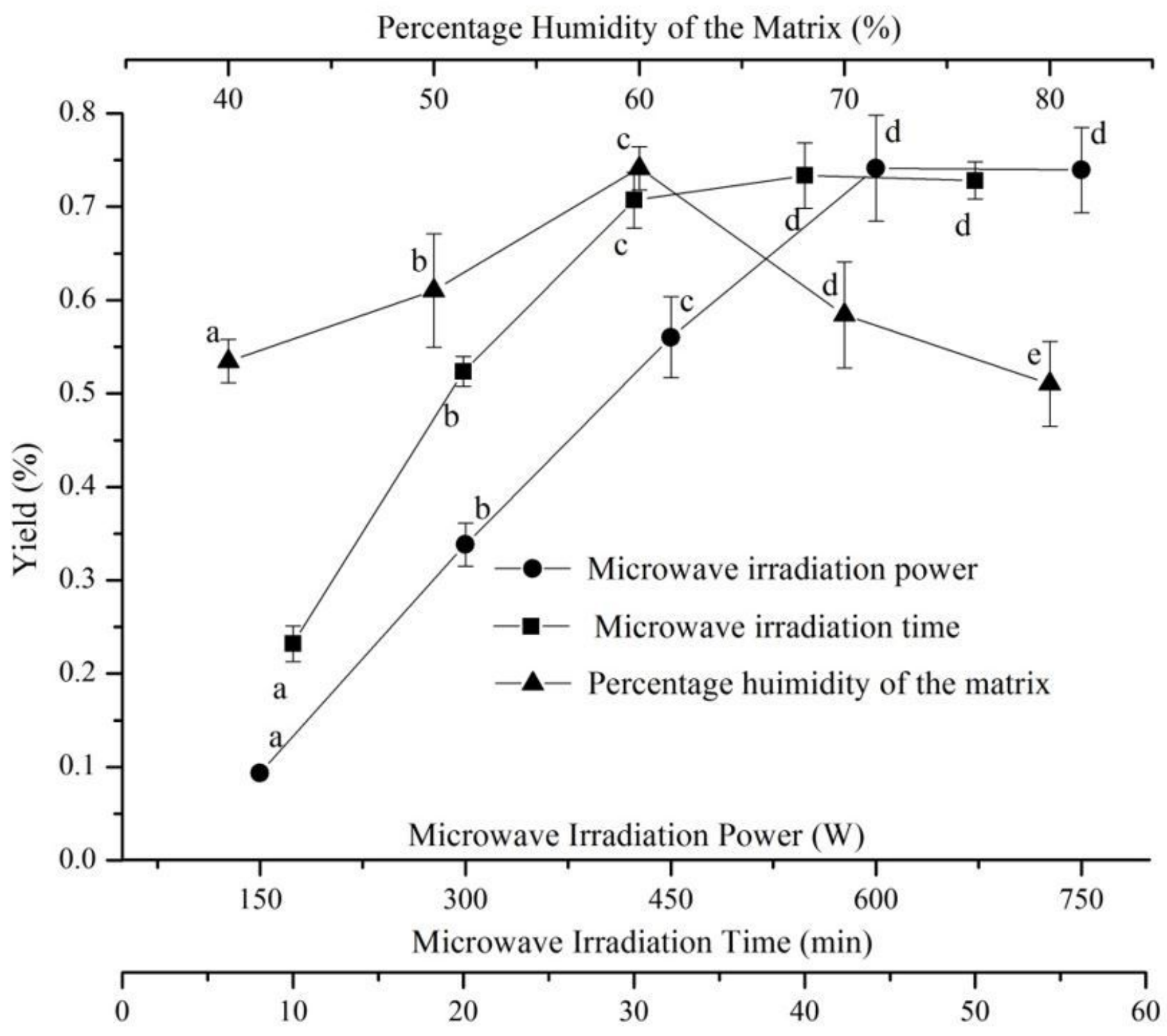

Figure 2

Effects of extraction time, microwave power, and percentage humidity of the matrix on EO yield from PL fruit 

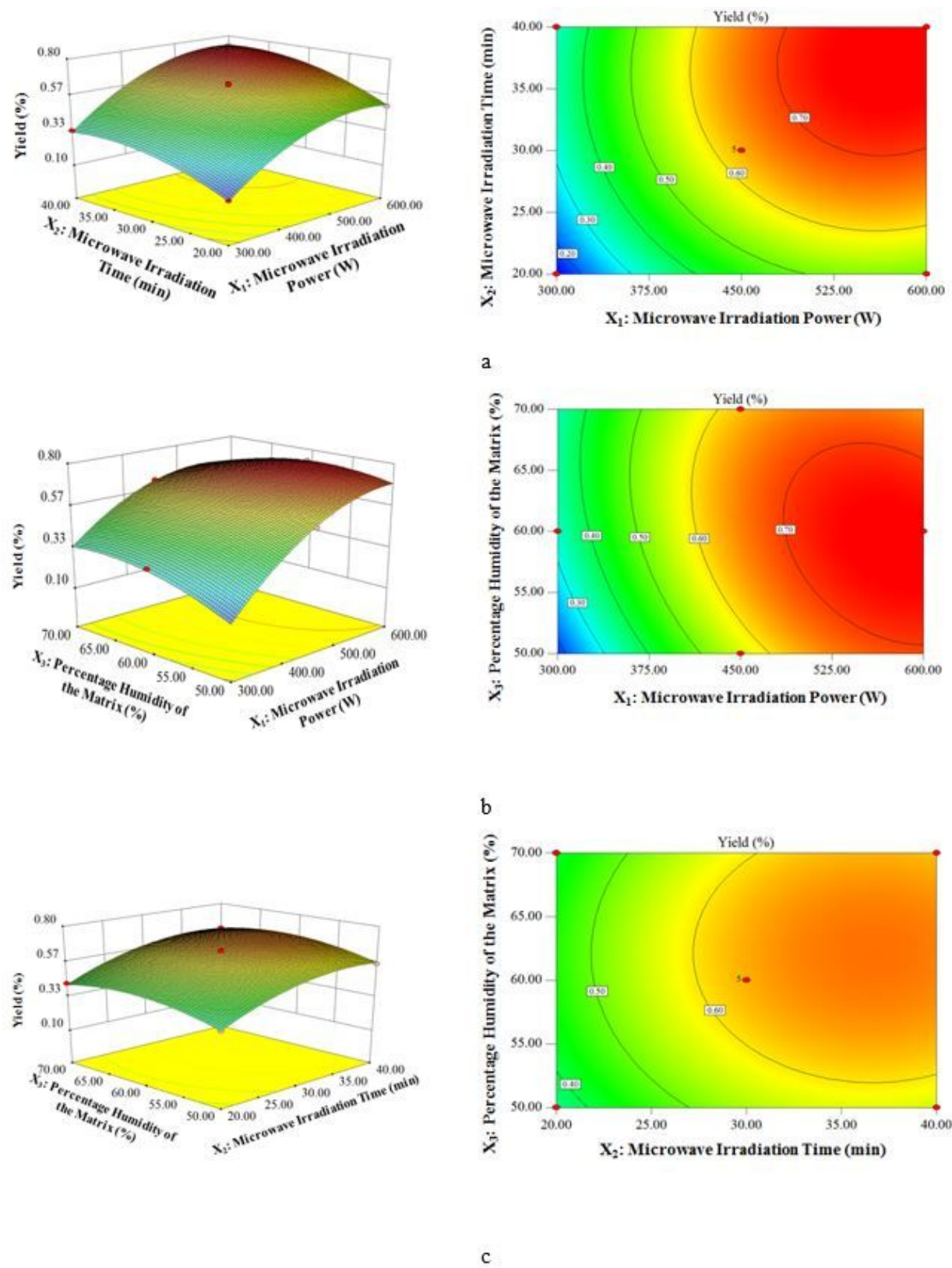

Figure 3

Response surface and contour plots. (a) Effects of microwave irradiation power and microwave irradiation time on PL EO yield, (b) effects of microwave irradiation power and percentage humidity of the matrix on PL EO yield, and (c) effects of microwave irradiation time and percentage humidity of the matrix on PL EO yield 